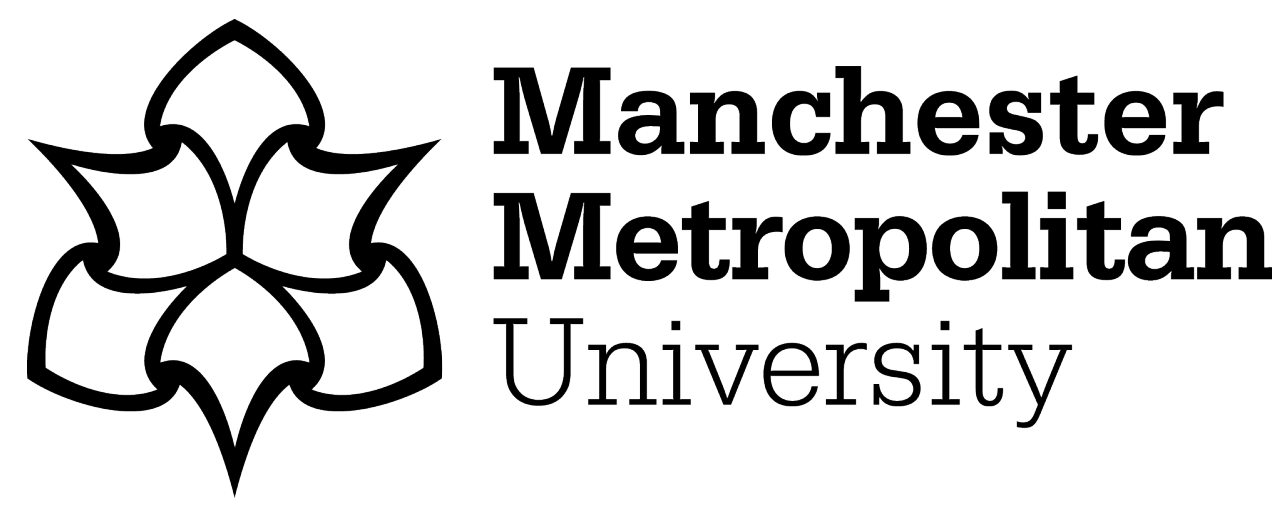

Brock, T (2017) Videogame consumption: the apophatic dimension. Journal of Consumer Culture, 17 (2). pp. 167-183. ISSN 1469-5405

Downloaded from: https://e-space.mmu.ac.uk/617975/

Version: Accepted Version

Publisher: Sage Publications Ltd.

DOI: https://doi.org/10.1177/1469540516684185

Please cite the published version 


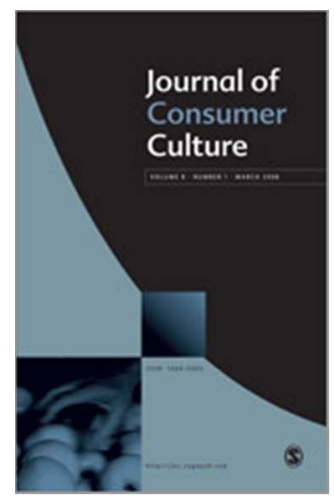

\section{Videogame Consumption: The Apophatic Dimension}

\begin{tabular}{|c|l|}
\hline Journal: & Journal of Consumer Culture \\
\hline Manuscript ID & JOCC-15-0077.R3 \\
\hline Manuscript Type: & Original Article \\
\hline Keywords: & Consumer culture, Video games, Griefing, Failure, Laughter, Apophatic \\
\hline Abstract: & $\begin{array}{l}\text { This article applies psychological-sociological accounts of the 'apophatic', a } \\
\text { form of negative thinking, to examples of gaming practices to } \\
\text { conceptualise a new theory of video game consumption. It challenges the } \\
\text { prevailing notion that the games consumer is always a 'cataphatic' thinker, } \\
\text { that is, an activistic, rational-pleasure seeker, and looks to the 'sorrows' } \\
\text { (Holbrook, 1993) of gaming to find evidence of its more undesirable } \\
\text { nature. The term apophatic is characterised as an attempt to de-value the } \\
\text { rational value purportedly placed on gaming practices. 'Griefing' other } \\
\text { players is a good example of this apophatic ethic; where players derive } \\
\text { value from the subversion of serious play through the disruption and } \\
\text { destruction of other players' game worlds. The struggle with 'failure' is } \\
\text { another. As such, the article concludes with a reflection on the almost } \\
\text { unsayable nature of videogame consumption, and suggests that consumer } \\
\text { value may be derived from its more negative, spiritual-like aspects. }\end{array}$ \\
\hline
\end{tabular}

\section{SCHOLARONE \\ Manuscripts}


1

2

3

4

5

6

7

8

9

10

11

12

13

14

15

16

17

18

19

20

21

22

23

24

25

26

27

28

29

30

31

32

33

34

35

36

37

38

39

40

41

42

43

44

45

46

47

48

49

50

51

52

53

54

55

56

57

58

59

60

Acknowledgements

The author would like to express his thanks to the anonymous reviewers who helped clarify the ideas presented in this article. 


\section{Introduction}

Apophasis is a common Greek designation for the language of negativity. Apophasis can imply 'negation', but its etymology suggests a meaning that characterises it closer to 'un-saying' or 'speaking-away'. Apo means 'from' or 'away'. Phasis means 'assertion'. Apophasis is thus commonly understood as 'denial', and is often paired with cataphasis, which means 'affirmation' or 'saying' (Sells, 1994, p.2).

The aim of this article is to explore the apophatic dimension of videogame consumption and to argue that consumers derive value from its more negative elements. Few have paid serious attention to the more undesirable aspects of videogames, such as the frustration that comes with 'failure' (e.g., the experience of loss through the death of an avatar) or the hurt that comes from 'griefing' (e.g., the intentionally harassing or upsetting of another player). I will argue that both of these elements of gaming practice appear to resonate with what Brown (1999) calls 'the apophatic ethic and the spirit the postmodern consumer'. The modern consumer is seen as someone who derives value from the negation of the rational value purportedly attributed to consumer behaviour in favour for its more 'hellish' aspects:

'For every manifestation of the Holy Spirit of Harrods or Hamleys, for every moment of extra-sensory bliss brought about by burying one's head in a bucket of Ben and Jerry's, there are encounters that only Mephistopheles himself and his mephitic marketing myrmidons could have concocted. Ironically, however, it is these abominable consumer experiences, these Stygian shopping torments, these infernal retailing regions, that render the pleasurable side of shopping so rapturous, exhilarating, joyous, spiritual - to some extent at least. An apophatic dialectic of good and evil, pleasure and pain, sacred and profane thus appears to obtain' (Brown, 1999, p.174).

This dialectic is of concern here also. From its earliest conception, the game consumer has been depicted as a rational pleasure-seeker, whose ability to control and play videogame environments well has been linked with an affirmative conception of enjoyment (Holbrook, et. al. 1982, 1984). Gaming pleasures have been portrayed as emerging from the achievement and success that players attribute to their mastery of gaming worlds (Grodal, 2000). An idea that is then enshrined in players' hedonistic daydreams and fantasies (Molesworth and Denegri-Knott, 2007) and life-scripts (Molesworth, 2009). Indeed, in recent years, it has become popular to talk of games as a rational escape from reality (McGonigal, 2011) and as an instrumental attempt to take control over the socio-economic risks and uncertainties present in late modern life (Molesworth and Watkins, 2014). In each case, videogames are seen to provide the consumer with a temporary relief from the disappointments of material reality, as it is said that what stimulates consumer desire to play more or newer videogames is the drive to overcome these imperfections (also see Campbell, 1987).

This article seeks to offer a new theory of the videogame consumer that moves beyond this conception of consumption as a rational, functional choice. Rather, it suggests that the games consumer derives value from the deeply conflictual, yet nevertheless profound challenges that are presented during play. I will argue that it is within the 'sorrows' (Holbrook, 1993) of videogaming that the consumer finds ways to introspectively connect to inner worlds by way of the elimination of gaming 
obstacles. To borrow from Nicos Mouzelis (2010), I argue that apophatic aspects of human reflexivity emerge as the consumer reflects on the struggles of gameplay. This has the effect of orientating human cognition away from the logico-deductive reasoning of rational choice towards more open-ended self-self and self-other relations. What this means is that the motivation to consume videogames is not solely instrumental, which requires an overly activistic conception of the human subject. On the contrary, what I will argue is that the videogame consumer mobilises a more 'passive observer-observed' mode of human reflexivity as they come to reflect on the meaning of their failures. This mode relies on the suspension of instrumental thinking and is seen to open up a space for players to connect more deeply to their gaming projects in both psychological and sociological ways.

To begin, I will consider sociological accounts of the apophatic, and I will reflect on its importance to theorising consumer behaviour. From this perspective, theories of the games consumer have tended to emphasise the cataphatic, that is, rational dimension of human behaviour. I will suggest that this position obscures the creative acts that emerge from the volatile nature of play, and that an understanding of its darker side yields a need to embrace the introspective, perhaps even spiritual side, of videogame consumption. 


\section{Videogaming: Pleasure through Control?}

The power of play over human psychology is well documented historically. Studies have argued that play is an overwhelmingly pleasurable experience (Deci, 1975). Play is understood to be autotelic: an intrinsically motivated behavior, which rewards people with an internal state of satisfaction and positive affect. When people play, they describe their playful experiences in terms of 'interest', 'excitement', 'enjoyment', and perhaps most importantly, 'pleasure' (Calder and Staw, 1975). A focus on these internal states has led to the phenomenological conceptualisation of play as a site for 'fun' (Lewis, 1982) and 'leisure' (Neulinger, 1981) as well as a site for 'flow' (Csikzentmihalyi 1975): a state of mind where the player is happy and in control.

This understanding of play has had a noticeable influence on consumer research into videogames, which suggests that consumer behavior is driven by these positive affective experiences (Holbrook et al., 1984; Holbrook and Hirschman, 1982). People feel good playing videogames, and it is the 'experiential' and 'hedonistic' side of consumer behavior that drives its consumption. One popular example of this is the pleasure that players derive from taking control over videogame environments. For example, Grodal (2000, p.211-212) argues that,

'Interactive media like video games create a further sophistication of media consumption by enabling consumers to switch between passive control of their emotional and cognitive states (by actively selecting one-way media) and an active control of these states (by choosing interactive media)'.

As such, videogames provide a way for people to take control over their moods and emotions, and derive satisfaction from the stimulation that comes with playing videogames well (also see Holbrook et al., 1984).

In recent years, this understanding of videogame consumption has been elaborated on to take account for the modern 'credo' of consumerism, perhaps the most significant contribution of which has come from the sociologist Colin Campbell (1987). According to Campbell, the desire for pleasure, as opposed to utilitarian need fulfillment, was driven by a disparity between imaginative anticipation of goods and the imperfect reality of consumer experiences. Disappointment with material reality propels a self-perpetuating desire for consumer experiences, which offers only momentary pleasure. As such, consumer research on videogames has tended to focus on the ways that players purchase and play videogames to help them actualize a sense of control over their lives (albeit momentarily). For example, Molesworth and Denegri-Knott (2007) have argued that videogame consumers use virtual collectable items as a way to control, order and make-sense of the 'liminality' in their lives. Here, videogames are said to be a resource for the scheduling of life-scripts, which provide players with the materials required to construct fantasies and daydreams about living better lives. Players use videogames not only to escape from routine (see Molesworth, 2009) but also to actualize a sense of progress in late modern life (see Molesworth and Watkins, 2014).

This perspective is built on a wider understanding that videogaming manipulates players into consuming products that facilitate the experiences of control, which they 
cannot get from material culture today. For example, Kirkpatrick (2013) has argued that videogame consumption is built on a wider rejection of material culture or, at least, a re-negotiation of its failures. These failures come in a particular form: that the modern world no longer offers rewarding work or the fulfilling of life opportunities needed to give people a sense of meaning. As such, the consumption of videogames provides a way to recuperate for this sense of loss by providing players with a means to ascertain a form of achievement and success that is rich in status symbolism. What emerges is evidence of players 'happy' to spend hours undertaking repetitive gaming acts, which is not only considered tantamount to the addictive nature of videogames, but also a means through which (the illusion of) control is said to temporarily remedy such liminal anxieties (Goggin, 2008).

The theme of control is not unique to theories of videogame consumption or consumer culture however. Mouzelis (2010) suggests that the idea of control is central to whole 'Western way' of thinking about reflexivity and the human subject.

Mouzelis calls it 'cataphatic reflexivity', and in his critique of European social theory, he argues that many prominent sociologists fall into the trap of conceptualising human subjectivity in terms of rational, instrumental action. Mouzelis' critique is broadly aimed at the 'reflexive modernisation thesis' of Beck, Giddens and Lasch (1994). Mouzelis is critical of their idea that the human subject is always seeking to rationally control and construct their biographies. For Mouzelis, our understanding of reflexivity and self-identity should not be limited to the notion that one seeks to take (biographical) control over the risks and uncertainties of late modern life. Such a position obscures the apophatic dimension of subjectivity, which is common to anyone who has thought reflectively about themselves and the challenges that they face. Mouzelis (2010, p.273) captures the 'apophatic' in the following way:

'An apophatic manner of turning inwards is another way of navigating in posttraditional settings. In ideal-type terms, in this case, the turning inwards aims not at doing but undoing, not at constructing but deconstructing. It aims at weakening rather than enhancing the rationalizing, calculating, planning dimensions of the self-self relationship. It focuses less on purposive decisionmaking processes and more on getting rid of the 'tyranny of purposiveness' [...] The same is true about identity formation. Identities are neither ascriptive nor cataphatically constructed. They emerge apophatically and so does the way they relate to each other'.

The apophatic is not about control, on the contrary, it is an attempt to negate instrumental rationality, and thereby shift away from cognition towards an exploratory, open-ended voyage that brings the subject closer to their inner world. In more secular terms, apophatic reflexivity is about finding a way to actualise the existential importance of introspection: an inward looking movement that offers a creative and dynamic widening of self-identity through feeling, rather than control and knowledge (also see Halton, 1995).

Such a perspective has been applied to consumer culture, though only very rarely. For example, Stephen Brown (1999, p.164), in his critique of Holbrook's 'Typology of Consumer Value', suggests that consumer behaviour is built on the very negation of what is often construed as 'valuable 'through cataphatic reasoning. To try and take control of consumer value by defining what constitutes 'Quality', 'Beauty', 'Fun', or 
'Moral' provides the very conditions of possibility for its re-evaluation via negativa and this may be understood as a deeply introspective process. From this perspective, consumption is imbued with a spiritual framing (see Lasch, 1979), which is derived from the seemingly transcendental nature of consumer encounters. Brown (1999, p.176) describes this nature as 'blasphemous buying', and it refers to the more 'hellish', almost purgatorial occurrences, which are an integral but nevertheless overlooked part of the consumer experience. It is our doubts, anxieties, tests, torments and temptations that supplicate our convictions and augment our commitments to consumer products.

To align Brown and Mouzelis then, what we see is that the motivation to consume is not strictly cataphatic, that is to say, an activistic attempt to derive pleasure from (momentary) episodes of control. On the contrary, to consume is also to turn inwards in a negatory fashion and passively-observe the false expectation that the object will deliver, thus eliminating it, whilst simultaneously bringing us closer to it. In other words, in this self-self relation, the consumption of the object is not about closure; it is not an attempt to achieve a goal. Rather, its negation prompts an open-ended dialogue with the self, which involves an ever-deepening, more intense cycle of introspection. Importantly, it is through this cycle that more spontaneous modes of being and acting in the world can emerge as we further examine others and ourselves via negativa. Both Brown and Mouzelis suggest that there is something profoundly spiritual in this process, for it is not an emergent property of rational thinking, but rather it is arrived at 'only through the seriousness, the pain, the patience and the labour of the negative' (Brown, 1999, p.165-166). In other words, it is our consumer abjection that puts us in touch with others and ourselves in ways deeper than that of the pleasure derived from control.

It is based on this understanding of consumer value that I seek to question the idea that the nature of videogame consumption can be explained only in terms of the pleasures derived from control. In the next section of this article, I will suggest that a reading of failure (as a loss of control) is important to understanding the apophatic value derived from the games consumer experience. 


\section{Apophatic Consumption: Failure in Videogames}

An exploration of the apophatic raises an important question with regards to the abject nature of videogame consumption: is failure a valuable consumer experience and, if so, why?

Games designer and researcher Jesper Juul (2013) argues that failure is one of the great paradoxes of videogaming - we may dislike failing in games but we dislike not failing even more. Indeed, it has long been acknowledged that the principle appeal of playing games is completing fair and challenging puzzles (Danesi, 2002). The more peculiar the puzzle, and the more uncertain its solution, the more we lose ourselves in trying to find its patterns and avoid its tricks - what the game designer might call 'good balancing' (also see Juul, 2011). Consider, for example, what it means to successfully complete a level in Sonic the Hedgehog: the player must be able to traverse the platform environment by avoiding the various hazards and traps that will kill Sonic. Failure to do so informs the player of a wrongdoing - Sonic has to survive to the end of the level - and the level is restarted to offer the player another opportunity. From this perspective, failure is said to motivate gameplay as it informs the player of whether or not they have solved the puzzle correctly, thereby acting as an obstacle to be rationally overcome, i.e., 'I will avoid jumping into that hole in the ground next time'.

I would suggest that there is an apophatic dimension to this act that has been overlooked. The appeal of failing in games reaches beyond this logical way to resolve a given puzzle. Indeed, we like failing in games because, like with other areas of consumption, we derive value from the emotional turmoil that accompanies it (also see Holbrook, 1993). In particular, I would suggest that Hegel's notion of 'the labour of the negative', adopted by Brown (1999), encapsulates this dimension: that one derives a sense of authenticity through the pain and seriousness that comes with failing in an antagonistic game world. The question is to understand how failures in videogames facilitate such abject experiences, and the psychological and sociological manner in which value is derived from them.

Generally speaking, the apophatic dimension of videogame consumption is built on two accepted assumptions within game studies. First, players have 'active conversations' (see Bogost, 2008) with the boundaries that videogames construct, including other players who play, e.g., in the case of online gaming. Second, these boundaries are designed to grant players the freedom from consequences. We like videogames despite acknowledging that we will fail, perhaps on many occasions. This is because games allow us to deny their judgment on our behavior. For example, we recognise that they are artificial designs that have been created to make players experience failure. Sometimes this fallacy is compounded with numerous bugs, glitches and the generally accepted issues of rendering, at least graphically, within a videogame (Juul, 2011).

These assumptions are important for understanding how games provide a way for players to plausibly deny the negative experiences that are derived from the failure of in-game performances. We can blame the game, we can blame a team-mate, we can even blame ourselves, but in a way that is cognizant, and perhaps even accepts, the pseudo-illusionary nature of the environment within which we are immersed. I stress 
the pseudo-part because it is this very ambiguity in play (see Sutton-Smith, 1997) that allows us to navigate failure in a way that makes it valuable.

Importantly, it is the intra-active relation that players establish with a videogame that makes it valuable. This is only possible because it relieves the player of a sense of agency. Players must forego a sense of control in recognizing that what is presented before them is designed (to varying degrees) to determine their behavior. They embrace the fact that the environment is a pre-designed unknown and a special set of rules and actions that circumscribe their capacity to play. For example, in order to win at Sonic the Hedgehog, I must accept the bounded control of the environment's physics engine, which circumscribes how fast I can run, jump and bounce. Similarly, I must accept that the levels progress in a sequential order and that I cannot know all the tricks and traps of each level before I play. To borrow from Mouzelis (2010, p.274), it is this very suspension of instrumental thought that facilitates the deeply personal connection that I have with the game. It is only through the delegating of a sense of my agency over to the gaming environment that I can initiate a "passive observer-observed' mode of reflexivity. This mode is not concerned with mastering the puzzle viz. logico-deductive reasoning, but rather establishing a sense of trust that I can have in the game as it guides me through its design (see Koster, 2013). Again, this is an intra-active relation because it emerges spontaneously as I entrust myself to the game's play mechanics. Thus, as I voyage through the levels of Sonic the Hedgehog, I am engaged in two active dialogues: I seek not only to negate its obstacles - to avoid its hazards - but also I recognise that failure is never the end. I trust that I can always return and start over. This relation acquires permanence and solidity so long as I understand what it is to fail, that is to say that the game does not change its rules, and as such I can derive value in acceptance of the game's eternal recurrence. In other words, my anger at the death of my avatar only turns me inwards as I entrust to the game the experience of what Holbrook $(1993, p .157)$ terms the 'rhetoric of rebirth': 'the joy lost through sorrow to joy regained'.

\section{Tragic Gaming}

That players are cognizant of the fact that they are playing within a special set of rules is key to understanding the abject value that consumers derive from playing videogames: videogames are mediums that provide a (relatively) safe space where players can experience tragic emotions.

Juul (2013, p.108-110) draws this out most clearly in his analysis of tragedy in games but the key point is that it is only possible because we feel able to relieve ourselves of a sense of responsibility for the characters involved (including the one we control) that we can experience of tragedy. He suggests that tragedy in games would not be possible otherwise - after all who would want to take control of Anne Frank and Anna Karenina without a clear sense of being relieved of responsibility? The irony for Juul is that players would probably take on these roles but that this would necessarily involve a kind of self-abnegation - much like watching Patrick Bateman in Mary Harron's film American Psycho; we distance ourselves from the atrocious murders he commits but we recognize the strategy behind how he hides the bodies as uncomfortable as this might be. The same is true of playing video games: when we fail we must acknowledge that we are ineffectual in some way. Such a feeling is selfabnegating, and yet we subject ourselves to it anyway because we trust in the possibility that there is a fair chance we might redeem ourselves. 
To extend Juul's analysis, I would argue that such feelings have a psychoanalytic framing that contain strong apophatic elements. The relationship between apophatic theory and psychoanalysis is well documented elsewhere (see Henderson, 2013), but it is worth noting that both theories emphasize the idea that an individual finds it deeply therapeutic to find and achieve goals on their own terms. The purpose of the analyst is not to suggest goals to the patient, but rather to have the patient become aware of those goals, in their own time, and eliminate them accordingly. What is said to emerge is an expression of self that is not imposed from the outside (i.e., by the analyst or the game) but rather as an intra-active relation that develops spontaneously from within the subject's inner world. This connection adds a layer of meaning to play that logico-deductive reasoning cannot, for it allows the player to experience emotional vulnerabilities, including fear, anger, sadness, and shock (see Sutton-Smith, 2003).

Consider, for example, the feelings of anger that accompany losing three or fours hours worth of gameplay. This is a very real possibility in the one of the most critically acclaimed, yet difficult, videogames ever produced: Dark Souls. Produced by Hidetaka Miyazaki, this action role-playing videogame is largely celebrated for the manner in which it subjects its players to combat encounters that often result in the experience of death and defeat. Internet commentary, including reviews and forum discussions, salute the game's ruthless nature: players who fail to proceed with extreme caution, learn from past mistakes, or find alternative routes to explore, will die. Indeed, 'you died' is the game's most infamous screen image as players find themselves time-again victim of the game's clever programming system. For in Dark Souls, enemy and boss battles are purposively designed to trick players into thinking that they have mastered their combatants' techniques. Players will spend hours cautiously learning how to defeat a single boss or a group of enemies only for the programming to change fighting style and to catch them off-guard. The result is death, and the player will be set back, often quite substantially, and asked to run the gauntlet again as if new.

Understandably, the prospect of losing hours of gameplay is rarely considered a pleasant experience in Dark Souls. And yet, it might be suggested that it is these cycles of struggle-death-rebirth that make it such a critical success. As one reviewer of the game suggests, 'Trying, failing, trying again, failing again - Dark Souls is an ongoing process of skin hardening, of toughening up... [it] intrinsically recognizes the importance of failing. You died. But you are back. You failed. But you can try again' (see Smith, 2016). Death makes for a good teacher in Dark Souls. It helps players transform the experience of failure into something therapeutic: a valuable lesson. Consider how the same reviewer reflects on the experience of death as analogous to his own neuroses:

'By the end of Dark Souls, I felt as if I had matured [...] I couldn't handle failure. And I don't mean failure as in professional failure, or even perceptible failure - if I so much as spilled a drink, or spent what I thought was too long getting ready in the morning, I would deteriorate into self-loathing. I might argue that Dark Souls mirrors what was once was my mental state [...] There were times, plenty in fact, when Dark Souls drove me to despair. It made me hate myself, scream at myself, hurt myself for being a failure - but maturity 
begins with confrontation. And contrary to its reputation, Dark Souls, for somebody acutely sensitive to personal or perceived failure, is immensely reassuring. By the end, I understood that making mistakes was not just acceptable, it was essential'.

This description clarifies the apophatic dimension of videogame consumption: it shows that a player who connects intra-actively to the abject experience of failure (through death) may derive a deep personal connection with this videogame. Dark Souls helps the player set his own goals, which he strives towards on his own terms; what emerges (within this sandbox environment) is a spontaneous expression of his will to eliminate challenging obstacles. This experience opens up the player to emotional vulnerability, which he observes and reflects on, informing how the game shapes his sense of self. What makes Dark Souls a critical success is that its cycles of struggle-death-and-rebirth help this player to reveal a personal tragedy (see Nietzsche, 1872 [1993]) - his neuroses. The game is experienced as a tragic drama, and rather than furthering the player's nihilism or obsession with rational control it becomes a means of confronting it and bringing it into check. Through fear, anger and sadness, the player comes to disclose a truth to themselves: that mistakes are not moments for mortification and self-flagellation but rather are an important, constructive, and necessary aspect of the human condition.

By way of the annihilation of their avatars, videogames offer the consumer remedial experiences that can help them confront their emotional insecurities. In the remaining section of this article, I want to further clarify this point through an analysis of the apophatic dimension of 'dark play'. In considering some of the most conflictual and perhaps upsetting gaming experiences around, I intend to show how laughter emerges as a cathartic and transgressive act that is important for establishing meaningful social relationships. 
The philosopher of play Miguel Sicart (2014, p.9-10) argues that one of the defining characteristics of play is that its pleasures are derived from a central tension between 'taking control' and 'letting go':

'Play is always dangerous, dabbling with risks, creating and destroying, and keeping a careful balance between both. Play is between the rational pleasures of order and creation and the sweeping euphoria of destruction and rebirth, between the Apollonian and the Dionysiac'.

Here, Sicart too makes reference to Nietzsche's (1872 [1993]) The Birth of Tragedy to suggest that central to the human psyche is a battle between rationality and irrationality. For Nietzsche, tragedy sums up the colliding tensions of Ancient Greek culture: between the order and sobriety of the Apollonian and the embodied, passionate, irrational, and irreverent Dionysiac art. Nietzsche considered how the genre of Greek tragedy effectively merged the two, allowing artists to move between both. Sicart (2014, p.9) argues that through play people find a way to navigate the Apollonian and Dionysiac tendencies in the human psyche (also see Caillois, 2001). He characterises this struggle in the following way: "not only with the obstacles and needs that play imposes on us, but also with the permanent temptations that happen in play'. In other words, when we play, we often find it tempting to break the rules or corrupt the very values appropriated to the playful context within which we reside. An example of this can be seen in Lego, we often find ourselves building things without the need for any plans or instructions - what Caillois (2001) refers to as the 'formal' or 'intrinsic' qualities of play. This is what makes it enchanting: it allows us to let go of the elements of rationality that typically structure our decision-making processes. We can even be reckless: building elaborate constructions only to make them unsteady and watch them as they are destroyed. Indeed, when we play in this manner, we can find that something very powerful emerges from the process of balancing (dis)order: laughter.

\section{Laughter as freedom}

Perhaps it seems odd to discuss laughter in an article about the negative experiences of videogaming, but for the Russian philosopher Mikhail Bakhtin (1984) laughter has a deep spiritual meaning that often emerges in dark times. He considers laughter to be one of the fundamental forms of truth concerning human nature, and suggests that certain aspects of the world are only accessible to laughter. One of these aspects is liberation: to laugh is to liberate oneself from external and internal censorship. It liberates us from prohibition and inhibition alike. Laughter is said to unveil within us a sense of renewal, one that leads us to reflect on the fallacy of seriousness itself. For Bakhtin, such liberation was encapsulated within the play activities found within the Carnival. Play was said to be an example of a 'carnivalesque activity': a way for people to express themselves by challenging the rational structures or institutions within which they operate. Humor or satire, key to the carnival, provided a way for people to open up a space for freedom, and this would be expressed through laughter. Carnivals were seen as ways of temporarily dismissing the oppressive forces of established rationality, and facilitating a space where people could be critical of the world in a deeply embodied way: people would laugh and hurt at the same time. 
Carnivals were not spaces of fun but, rather, catharsis; they functioned to provide a space to purify the soul through ambivalent laughter, and to provide a ritual that could supplant religious austerity. As such, laughter is at its most powerful when it takes on an intra-active form of truth: when it gets the subject to question his or herself and their relationship to nature and/or other people.

Videogames are spaces filled with laughter. But to understand why, one needs to move beyond the widespread assumption that videogaming is a 'normatively positive' and voluntary experience (Malaby, 2007). Indeed, such an assumption obscures the dark and playful attitude that often penetrates the formal design of games, opening them up to carnivalesque activity. For example, Mäyra (2015) talks of 'dark play' as an approach to play situations in which one finds anarchic pleasure in the breaking, smashing and failure of gameplay. Through examples of Lego Star Wars and Lego: The Lord of the Rings, Mäyra argues that laughter may be commonly associated with the tragedy of failure and (more broadly) the 'playful destruction' found in videogame environments: children are often found excitedly demolishing in-game surroundings, or laughing at the humorous tragedies that befall Lego characters. Under the control of children, Lego-characters appear to die under the most calamitous of circumstances, argues Mäyra (2015, p.95), and these episodes of dark play are said to demonstrate, 'how the ambiguities of power and transgression in play are intertwined in complex renegotiations of (active or passive) agency and of new realities generated in play'. In other words, videogames provide children with the space to let go of the seriousness of the very subject material presented, and thereby explore the morality of violence and death through the laughter that accompanies failure. This relieves them of (some of) the agency that life and death decisions bring, whilst also introducing them to the funny side of our controlling, existential being.

\section{Griefing 'for the lulz'}

Conceivably a more extreme example of this is 'griefing' (or 'trolling'), where a player intentionally ruins the gameplay experiences of another 'for the lulz' (laughter). Griefing is commonly defined in the negative. For example, Warner and Raiter (2005, p.45) argue that griefing is the 'intentional harassment of other players' through the utilisation of game structures or physics 'in unintended ways to cause distress for other players'. Chesney et al., (2009) suggest that the practice is common within online worlds, such as Second Life, where griefers proceed to play games to make trouble and irritate others. Some examples include:

- Entering a player-owned house or establishment and blocking entrances/exists, thereby delaying the gameplay of others.

- Spamming the in-game chat with vulgar and obscene language or symbolism.

- Hacking accounts, crashing servers and orchestrating large in-game events that subvert the control and restrictions of the game players and server administrators.

Understandably, those on the receiving end of this kind of play tend to find it, at least to begin with, emotionally upsetting. The imposition of having one's hard earned efforts destroyed or tainted is souring to say the least. It prompts us to question the time and effort we've put in, only to have our project(s) miscarry. Foo and Koivisto (2004) suggest that victims of griefing often dismiss the activity as a simple maleficent attempt to frustrate and harm other players. Indeed, it is said that griefers' 
actions are pointless and have no intrinsic value - why, after all, would anyone seek to subvert the structures of rationality and control designed into the game?

A more nuanced perspective would appreciate the apophatic character of griefing, and suggest that it is an example of how players will turn the serious treatment of gameplay 'on its head' to find another layer of meaning (also see Schrank and Bolter, 2014). Bakioglu's (2009) analysis of 'Goon Culture' in Second Life resonates strongly with this. Bakioglu argues that the origins of griefing in online videogames can be traced back to web forums that were orientated towards subverting the use of the Internet for serious business. 'Goons' were videogame players who would object to the serious treatment of videogame play through their creative and disruptive gameplay styles. This would include attacking players, hacking accounts and crashing services 'for the lulz'. Griefers find it funny telling and showing others that they should not take this videogame too seriously. Indeed, O'Brien (2010) argues that griefing in Second Life is an example of 'theatrical play': it threatens the authenticity of the immersive environment precisely to prompt users to contemplate the value that they attribute to it. From this perspective, griefing negates the seriousness with which people immerse themselves within these worlds. It is a transgressive act; a cheap shot, perhaps, but one which is conducted in order to elicit a laugh and open up a space for frivolity, which can bring griefers and victims into emotional contact with one another.

The idea that victims of griefing may find it funny should not be so alien. As with an apophatic account of failure, players may find griefing confrontational, yes, but it is also therapeutic to have the veil of control lifted from one's eyes. There is a humorous sense of relief in accepting that one's effort to control things has been annulled. The Slovenian philosopher of comedy Alenka Zupančič $(2008$, p.143) captures this point when she discusses politically incorrect jokes: these jokes should cause a kind of 'existential anxiety' but instead a 'certain amount of pleasure gets realized and makes it possible for us to laugh also in [sic] face of its discomforting dimension'. To have one's gaming efforts ridiculed or attacked operates in a similar manner: it confronts the player by exposing the arrogant pretentions of their arbitrarily created order(s). Like failure, griefing has a remedial capacity then: it creates the conditions of possibility for players to turn inwards (intra-actively) and find humility in the funny side of dark play.

Importantly, such experiences are not only psychological in character, for laughing at one's own or another player's misfortune is also a 'social performance', which can bind players together within a group or larger community (Goffman, 1967). For example, Conway (2013) argues that laughter, whilst cathartic, is also an important part of any video gamer's communicative apparatus. Laughter is a point of socialization that can give players license to engage in conversation, perhaps even with complete strangers. Laughter is said to be an example of how 'phatic interaction' (2013, p.22) emerges within gaming communities: a player will use laughter in order to confirm their own reaction to a particular incident by way of conferencing with another that they are 'on the same page'. As such, it may be suggested that players embrace the hostility of the carnivalesque as a way of establishing inter-active cues that can foster social cohesion. 
Consider, for example, the kinds of 'grief play' found in pre-match lobbies of online first-person shooters, like Call of Duty (see Meades, 2015b, p.65-68). Trash talking, ridicule, and ritualistic laughter are all examples of the social cues that operate apophatically in this space- they negate the terms of service because their manifestations are found to be offensive, problematic and abject. And yet, they are also social cues that validate members of the group as 'normal'. Ridiculing someone for a tragic kill-death ratio/score in Call of Duty is a rite of passage, which players recognise as part of acting appropriately within the game's frame. By laughing at a poor score, players are given license to 'laugh it off': to remedy the disappointing play experience and the tense social situation that may follow. Laughter 'breaks the ice' of playing poorly, and sees players acknowledge to one another that 'mistakes happen', or that it is 'just a game'. These cues are important for experiencing a sense of social cohesion within online gaming environments, particularly as laughter operates to lessen social responsibility.

In closing, I would suggest that there is a role in videogame consumption for the Jester as well as Master - the licensed fool whose inappropriate behavior confronts and keeps in check the seriousness with which other players treat the game. In making jokes, and playing incorrectly, the Jester can become an accepted part of a player's social performance. They ridicule but also laugh at their own efforts in an attempt to subvert the instrumental structures that typically characterize 'playing well' (see Kirkpatrick, 2013; also Meades, 2015b). From this perspective, the Jester is an apophatic character: someone whose mischievous and risky behavior is acknowledged (perhaps even celebrated) as a way to invite players to think intra-actively about their gaming practices. Thus, the fool who kills himself and his teammates in calamitous ways (e.g., by throwing a poorly-timed grenade out of a closing elevator) sets fourth the possibility for all those involved to become a little bit closer: to laugh and recognise that there is more to gaming than rational control. 


\section{Conclusion}

By referring to psychological and sociological accounts of the 'apophatic', a form of negative thinking, and applying this to examples of gaming practices, I have tried to show that videogame consumption is not only motivated by affirmative pleasures, but is negatory in the form that it takes. This culminates in a new theory of the videogame consumer that is built on the following assumptions:

1. The consumer connects with videogames in both intra-active (self-self) and inter-active (self-other) terms. In the cataphatic case, the consumer connects with the game in an activistic manner as an object to be instrumentally overcome. In the apophatic case, the consumer connects with gameplay as an open-ended voyage to be observed and commented on passively. The latter is important because it opens up consumer studies to helping explain the more 'hellish' aspects of gameplay, particularly the appeal of 'playing darkly' (Meades, 2015b, Mortensen, et al. 2015).

2. Playing a videogame is often an unknown and uncertain experience. One's perception of what is controllable is contingent upon our interactions with the design of the game and other players. As such, videogames should be understood as oblique (Kay, 2011) environments that are premised on a player 'mucking through' disappointment, failure and frustration. As such, videogame consumption may be driven by not getting what one is looking for as opposed to a pre-conceived notion of self-realisation/self-actualization. What is perhaps spiritual about playing video games is that consumers may derive a sense of (self-) knowledge and expression from the process of negating previously unknown obstacles established through their gaming journey.

3. From this perspective, a discussion of the apophatic allows us to acknowledge that consumers can connect with themselves and others on a level beyond means-ends thinking. This provides mutual grounds for the recognition of what Brown (1999) calls 'the labouring of the negative' in consumer value that players credit one another with expressions of solidarity that emerge from the most frustrating, perhaps even hurtful aspects of their consumption. Psychoanalysis helps us understand the intra-active aspects of this consumption as a remedial catharsis built on a relational trust between the player and the game. Symbolic interactionism helps us understand the interactive aspects of this consumption as a social performance built on openended phatic interactions that prompt social solidarity and (a momentary) critical stance towards the seriousness of playing well.

Each of these points captures the tensions that characterise videogame consumption: between the cataphatic and apophatic, affirmation and denial, winning and losing, pleasure and pain, sadness and laughter, control and letting go. As such, videogaming may be considered an example of what Bateson, et al., (1956) terms the 'doublebind': a somatic practice that carries conflicting messages that result in an emotionally charged dilemma. Such dilemmas are evident in players' deep intra- and inter-personal struggles with the possibility of defeat. Interestingly, Bateson noted that there was a spiritual dimension to this dilemma, as in attempting to transcend the constraints of its dualism, subjects would recognise the impermanent nature of their reality. This article has shown that videogame consumers may too experience such 
transcendence. Videogames offer them a sense of redemption through the annihilation and re-birth of their avatars. That such deliverance is possible speaks to the contradictory manner in which players experience and value the desire for dis (order). That games consumption is an act of negative labouring, and that one may derive spiritual meaning from its black magic, points to its tragic and yet alluring quality. 


\section{References}

Bakhtin, M. M. (1984). Rabelais and his world, Indiana University Press.

Bakioglu, B. S. (2009). "Spectacular interventions of Second Life: Goon culture, griefing, and disruption in virtual spaces." Journal For Virtual Worlds Research $1(3)$.

Bateson, G., D. D. Jackson, J. Haley and J. Weakland (1956). "The double bind." Behavioral Science 1(4): 251-254.

Beck, U. Giddens, A. Lasch, S. 1994. Reflexive Modernization: Politics, Tradition and Aesthetics in the Modern Social Order. Stanford University Press: California.

Bogost, I. (2008). "The rhetoric of video games." The ecology of games: Connecting youth, games, and learning: 117-140.

Brown, S. (1999). "The apophatic ethic and the spirit of postmodern consumption." Consumer value: a framework for analysis and research: 159 .

Caillois, R. 2001. Man, Play and Games. University of Illinois Press: Chicago.

Calder, B. J. and B. M. Staw (1975). "Self-perception of intrinsic and extrinsic motivation." Journal of personality and social psychology 31(4): 599.

Campbell, C. (1987). The consumer ethic and the spirit of modern hedonism, London: Basil Blackwell.

Chesney, T., I. Coyne, B. Logan and N. Madden (2009). "Griefing in virtual worlds: causes, casualties and coping strategies." Information Systems Journal 19(6): 525-548.

Consalvo, M. 2007. Cheating: Gaining Advantage in Videogames: London: MIT Press.

Conway, S. 2013. Argh!: An exploration of the response cries of digital game players. Journal of Gaming and Virtual Worlds, 5(2), pp.131-146.

Csikszentmihalyi, M. (1975). Play and intrinsic rewards. Journal of humanistic psychology. 15(3), p41-63.

Danesi, M. (2002). The puzzle instinct: The meaning of puzzles in human life, Indiana University Press.

Deci, E. L. (1975). Intrinsic motivation. New York: Plenum.

Foo, C. Y. and E. M. Koivisto (2004). Defining grief play in MMORPGs: player and developer perceptions. Proceedings of the 2004 ACM SIGCHI International Conference on Advances in computer entertainment technology, ACM.

Goggin, J. (2008). "Gaming/gambling: Addiction and the videogame experience." The pleasures of computer gaming: Essays on cultural history, theory and aesthetics: 33-51.

Goffman, E. 1967. Interaction Ritual: Essays on Face-to-Face Behaviour. Garden City, NY: Doubleday, Anchor Books.

Grodal, T. (2000). 'Video games and the pleasures of control'. In D. Zillmann and P. Vorderer (Eds.) Media entertainment: The psychology of its appeal, Lawrence Erlbaum Associates.

Halton, E. (1995). The modern error: Or, the unbearable enlightenment of being. In M. Featherstone, S. Lasch, and R. Robertson (Eds.) Global modernities. London: Sage.

Henderson, D. 2013. Apophatic Elements in the Theory and Practice of Psychoanalysis: Pseudo-Dionysius and C.G. Jung. London: Routledge.

Holbrook, M. B., R. W. Chestnut, T. A. Oliva and E. A. Greenleaf (1984). "Play as a consumption experience: The roles of emotions, performance, and personality in 
the enjoyment of games." Journal of Consumer Research: 728-739.

Holbrook, M. B. and E. C. Hirschman (1982). "The experiential aspects of consumption: Consumer fantasies, feelings, and fun." Journal of consumer research: 132-140.

Holbrook, M. B. 1993. Romanticism and sentimentality in consumer behavior: a literary approach to the joys and sorrows of consumption, In M.B. Holbrook and E.C. Hirschman (Eds.) The Semiotics of Consumption: Interpreting Symbolic Consumer Behaviour in Popular Culture and Works of Art, Berlin: Mouton de Gruyter.

Juul, J. (2011). "Half-real: Video games between real rules and fictional worlds."

Juul, J. (2013). The art of failure: An essay on the pain of playing video games, Mit Press.

Kay, J. 2011. Obliquity: Why our goals are best achieved indirectly. Profile Books: London.

Kirkpatrick, G. (2013). Computer Games and the Social Imaginary. Cambridge, Polity Press.

Koster, R. (2013). Theory of fun for game design, O'Reilly Media, Inc.

Lasch, C. 1979. The Culture of Narcissism: American Life in an Age of Diminishing Expectations. W.W. Norton: New York.

Lewis, M. (1982). Play as whimsy. Behavioral and Brain Sciences 5(01): 166-166.

Malaby, T. M. (2007). "Beyond play a new approach to games." Games and culture 2(2): 95-113.

Mäyrä, F. (2015). Little Evils. In Torill Elvira Mortensen, Linderoth, J, Ashley ML Brown (Eds.) The Dark Side of Game Play: Controversial Issues in Playful Environments. London, Routledge.

McGonigal, J. (2011). Reality is broken: Why games make us better and how they can change the world. Jonathan Cape, London.

Meades, A. 2015b. Understanding Counterplay in Video Games. London, Routledge.

Molesworth, M and Denegri-Knott, J. 2007. Digital play and the actualization of the consumer imagination. Games and Culture, 2, 114-133.

Molesworth, M. (2009). "Adults' consumption of videogames as imaginative escape from routine." Advances in consumer research 36(1): 378-383.

Molesworth, M. and R. D. Watkins (2014). "Adult videogame consumption as individualised, episodic progress." Journal of Consumer Culture: 1469540514528195.

Mortensen, T, Linderoth, J, Ashley ML Brown (Eds.). 2015. The Dark Side of Game Play: Controversial Issues in Playful Environments. London, Routledge.

Mouzelis, N. (2010). "Self and Self-Other Reflexivity: The Apophatic Dimension." European Journal of Social Theory 13(2): 271-284.

Neulinger, J. (1981). To Leisure: An Introduction. Allyn \&Bacon Boston, MA.

Nietzsche, F. 1872 [1993]. The Birth of Tragedy: Out of the Spirit of Music. Penguin Books: London and New York.

O'Brien, S. (2010). "Serious Play: Performance, Death and Theatricality in Second Life." Videogame Studies: 113.

Schrank, B. and J. D. Bolter (2014). Avant-garde Videogames: Playing with Technoculture, MIT Press.

Sells, M. A. (1994). Mystical languages of unsaying, University of Chicago Press.

Sicart, M. (2014). Play Matters, MIT Press.

Smith, E. (2016). 'Dark Souls: The video game version of my neuroses taught me the importance of failure'. International Business Times. Website link: 
http://www.ibtimes.co.uk/dark-souls-video-game-version-my-neuroses-taughtme-importance-failure-1554686 - accessed 1st August 2016.

Sutton-Smith, B. (1997). The ambiguity of play. Harvard University Press

Sutton-Smith, B. (2003). "Play as a parody of emotional vulnerability." Play and culture studies 5: 3-18.

Warner, D. and Raiter, M. 2005. Social Context in Massively-Multiplayer Online Games (MMOGs): Ethical Questions in Shared Space, International Review of Information Ethics, 4, 47-50.

Zupančič, A. (2007). The odd one in: On comedy, MIT Press: Cambridge Massachusetts. 


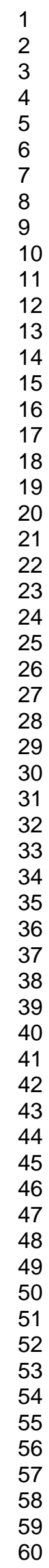

